DOI 10.37882/2223-2982.2021.01.38

\title{
ПАРАДИГМАТИЧЕСКИЕ СВОЙСТВА ФРАЗЕОЛОГИЧЕСКОЙ ЕДИНИЦЫ (“НЕТИПИЧНЫЕ ФРАЗЕОЛОГИЗМЫ" В КИТАЙСКОМ ЯЗЫКЕ)
}

\section{PARADIGMATIC PROPERTIES OF A PHRASEOLOGICAL UNIT ("ATYPICAL PHRASEOLOGICAL UNITS" IN CHINESE)}

Chen Xue

Summary: The article analyzes the characteristics of phraseology in modern Chinese linguoculture from different angles. The polemics of concepts of phraseological units (PU) in living speech and literary work from the point of view of syllabeme, morphology and syntax are noted. A diagram is drawn, which shows the results of collecting and analyzing information about the winners of the previous Mao Dun Literature Prize. Some unsolved issues in idiomatics field are shown that need to be further studied in the future in the Chinese linguistic culture.

Keywords: phraseology, polemics of phraseological units, Chinese linguoculture, grammatical properties of idioms, functioning of idioms, atypical phraseological units.

\section{Введение}

$\mathrm{P}$ обота посвящена изучению актуальной проблемы фразеологии в китайской лингвокультуре с разных сторон. Особое внимание уделяется вопросам специфики и различия в паремиях рассматриваемых языков. В данной работе с помощью теории многомерности, антропоцентричности, аксиологии и иерархичности анализируем языковые сознания.

\section{Основная часть}

Чэнъюй - это особая форма лексики в китайском языке, их изучение в рамках современного языка началось после возникновения литературы на байхуа (с двадцатого века). Они могут быть поняты как общепринятые устойчивые обороты в китайском языке. Сам термин 成 语(чэнюй) можно рассмотреть по компонентам, где 成 означает "завершать, заканчивать, формировать", в иероглиф 语-"фраза, изречение, язык” [4,с.53]. Поэтому с точки зрения наименования в китайском языке идиомы относятся к категории "язык". Это отличается от значения меньшей прагматической единицы - "слово" или "китайский иероглиф". В разговорной речи идиомы часто используются в качестве основного компонента в предложениях, и в этом случае они эквивалентны "словам." Поэтому в китайском языке идиомы часто понимаются

\author{
Чэнь Сюе \\ Аспирант, Государственный институт русского языка \\ им А.С. Пушкина, Москва \\ 437118032@qq.com
}

Аннотация: В статье с разных сторон анализируются характеристики фразеологии в современной китайской лингвокультуре. Отмечаются полемики концептов фразеологических единиц (ФЕ) в живой речи и литературном произведении с точки зрения силлабемы, лексики и синтаксиса. Показываются некоторые нерешённые фразеологические вопросы, которые необходимо дополнительно изучить в будущем в китайской лингвокультуре.

Ключевые слова: фразеология, полемика концептов ФЕ, китайская лингвокультура, грамматические свойства идиомов, функционирование идиомов, нетипичные фразеологизмы.

как“фиксированные фразы”.

По этой причине, определение китайской лексики часто модифицируется до “суммы слов и фиксированных фраз". В китайской лингвистике «словосочетание» является особой интересной для изучения категорией. Так в грамматической структуре китайского языка 词 "слово" обычно используется как компонент предложения. Но в некоторых случаях одно "слово" не является завершенным по смыслу, а значит их нужно объединить в группу из нескольких единиц, чтобы сформировать полное предложение. Такое сочетание, состоящее из нескольких слов, объединенных в качестве компонента предложения, называется "фразой". "Устойчивое словосочетание" состоит из "слов", однако это не языковая единица, которая составляла бы целое предложение. Таким образом, можно сделать вывод, что "устойчивое словосочетание" является некой языковой единицей между "словом" и "предложением". Сегодня многие китайские учёные считают, что "устойчивое словосочетание" не является языковой единицей первого уровня "слова". Поэтому лингвисты утверждают, что оно должно именоваться "фразой".

Также, исходя из этого положения, мы можем сделать следующий вывод: "устойчивое словосочетание" более обширное явление, чем "слово". И более замкнутое, и не- 
делимое, чем “словосочетание”.

В современном китайском языке фразеологизмы имеются следующие типичные характеристики: большинство из них состоят из четырёх иероглифов; их форма устойчива; семантическая степень прозрачности достаточно низкая, так как они произошли из классических сюжетов.

Словарь “Энциклопедия Китайских идиом" 《中文成 语大全》 насчитывает около 17934 фразеологических выражений, где: 17140 идиом состоят из четырех слогов (95.57\% от общего количества) [5,с.238].

Если мы будем определять и оценивать фразеологизмы с помощью вышеописанного положения, то сможем обнаружить, что в китайском языке есть некоторые "нетипичные идиомы". Китайский лингвист Цяо Юн в его произведении 《Количественное и качественное исследование определения идиом и критериев》 《成语鉴别与 成语词典收词标准的量化定性研究》[6,c.126-128]. предлагал семь основных фразеологических характеристик: устойчивость; параллельное соединение ("2+2", например фразеологизм со слогом 风风火火 fēngfēnghuǒhuǒ); латентность; замкнутость; элегантность; историчность и идиоматичность. Цяо Юн считает, что если основные характеристики соответствуют вышеприведенным семи, то, конечно же, перед нами будет идиома. Те, что соответствуют вышеприведенным пяти характеристикам, тоже могут быть причислены к идиомам[6,с.376]. Согласно мнению Цяо Юна, выражение 喝西北风 (hē xīběi fēng) (буквально это обозначает “питаться северо-западным ветром"; в вольном переводе: "голодать, жить впроголодь, жить в нужде") тоже быть причислены к группе фразеологизмов. С точки зрения синтаксиса эта фраза является глагол-допонительной структурой, которую: нельзя разделить, нельзя произвольно добавить другую морфему (внутренняя структура достаточно устойчива).
В ходе работы с материалами Литературой премии Мао Дуня мы обнаружили, что почти каждым победителем было использовано данное выражение.

Таким образом, выражение 喝西北风 совпадает соответствует критериям устойчивости, стабильности, замкнутости и всеобщности. И поэтому мы можем утверждать, что 喝西北风 - это фразеологизм.

Но с точки зрения фонетики, слоговое строение этого выражения выглядит как "1+3", что, очевидно, не соответствует характеристике параллельного соединения. Если обратиться к истории, фраза 喝西北风 впервые была использована в произведении “Неофициальная история конфуцианцев" (роман У Цзинцзы, который был опубликован во время династии Цин), История этой фразы не очень длинная (около 300 лет до н.э.), поэтому не совпадает с этой нормой.

В аспекте языкового стиля можно привести следующий пример: “我一天杀一个猪,还赚不到钱，都给你去丢 在水里,叫我们一家老小喝西北风吗?"(《儒林外史》3回) [4,c.205]. (Перевод: “В день зарезаю одну свинью, но всё ещё не могу заработать деньги. И ты все накопления потратил, что всей нашей семье от мала до велика делать, святым духом питаться ("питаться северо-западным ветром")? ("Неофициальная история конфуцианцев", третья глава). Бесспорно, фраза 喝西北风 здесь использована больше в разговорном стиле, что не соответствует характеристике элегантности. Поэтому мы можем причислить выражения к группе "фразеологизма нетипичного".

Существует также иная ситуация, когда обычные словосочетания состоят из четырёх слов, но не могут быть отнесены к фразеологизмам. Причина в том, что в данных выражениях недостаточно выражена аллюзия. И поэтому, с точки зрения современного китайского языка, фразеологические обозначения являются языковыми

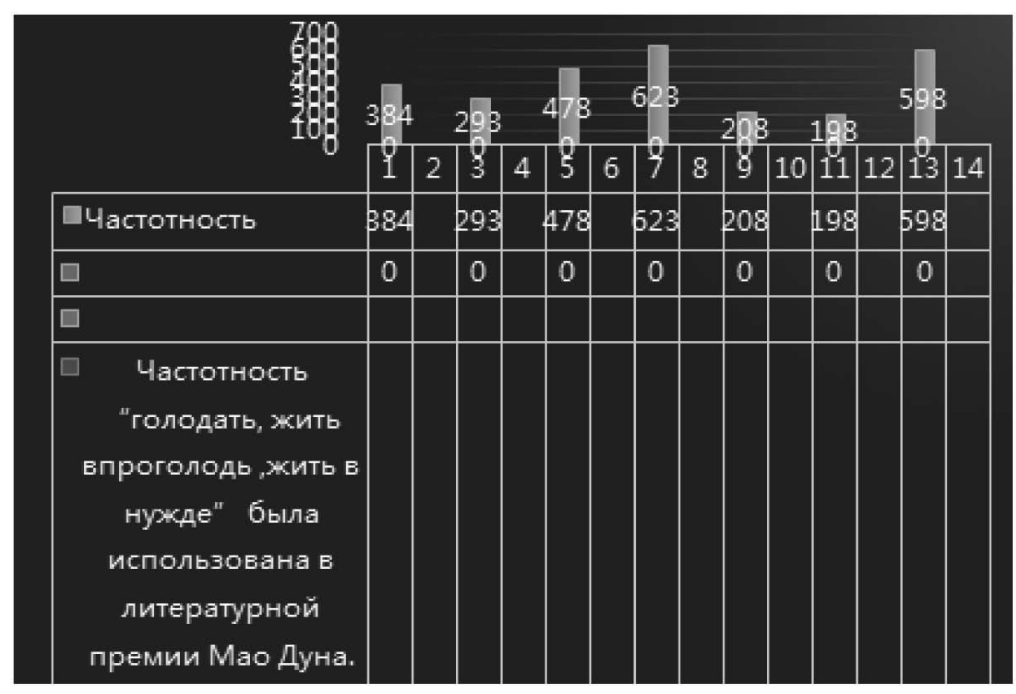

Таблица1. 
единицами в форме словесного оформления.

Конкретные проявления нижеследующие:

1. В текстах фразеологизм - это составляющая предложения, которая на грамматическом уровне эквивалентна слову.

2. Составляющие компоненты многих идиом в настоящее время утратили способность независимо складываться в словосочетания, становиться выражениями на литературном языке вэньянь.

В современном китайском языке очень мало идиом, состоящих полностью из фразеологической морфемы (дальше в статье ФМ), некоторые идиомы кажутся состоящими из ФМ, но они не могут составлять слова, выражая какой-то смысл. Например: 跋山涉水(báshānshèshuॉ): исходить горы, переходить реки. Хотя иероглиф 水 “вода" можно отнести в группу отфразеологического словаобразования, однака при образовании выражения о 河流 “реке" иероглиф 水“вода" нельзя использовать. [1, с. 312] Потому что люди не говорят “одна вода", а только “одна река" или "река".

3. Некоторые фразеологизмы сохраняют грамматические характеристики и грамматические отношения древних китайских языков, и именно по этой причине некоторые идиомы имеют прочную структуру и собственную окраску.

4. Фразеологизм=словосочетание: к такому тезису можно прийти в результате анализа древнего китайского языка. А в современном китайском языке, фразеологическая единица, как семантема, должна оцениваться уже по критериям современного китайского языка. В современном китайском языке эти типичные идиомы завершили процесс трансформации от фразы к слову.
Однако, как особая часть китайской лексики, употребление идиом существенно отличается от употребления обычных слов. Идиомы обычно имеют следующие характеристики: изящные, образные, яркие. Идиомы, выражающие релевантное значение, становятся приоритетными, когда люди хотят подчеркнуть часть дискурса в выражении. В современном китайском языке лингвисты проявляют больший интерес к изучению риторической функции, исторических источников и культурной окраски. А грамматические свойства идиомов и их функционирование в структуре предложения не получили достаточного внимания. Это даёт нам больше возможностей для изучения в данной области.

\section{Зак^ючение}

C XX века изучение китайских идиомов достигло больших успехов. Многие лингвисты внесли свои большие вклады в этой сфере. Характеристики типичных фразеологизмов в китайской лингвокультуре на данный момент, как учёные указывают:

1. состоят из четырёх иероглифов,

2. их форма устойчива,

3. семантическая степень прозрачности достаточно низкая, так как они произошли из классических сюжетов.

Но до сих пор, есть ещё некоторые нерешённые вопросы, которые необходимо дополнительно изучить в будущем. Например, основные критерии определения "нетипичных идиомов"; значение слов; общее значение идиома; этимологическое значение; грамматическое значение и риторическое значение в обрасти фразеологии. На сегодняшний день, к этим вопросам не достигли общего познания. И поэтому нам нужно продолжить исследования.

\section{ЛИТЕРАТУРА}

1. Бредис М.А. Балтийская паремиология от истоков до современности: подходы к изучению и определению пословиц в латышском и литовском языках // Филологические науки в МГИМО: Выпуск 4 / Гл. редактор С. В. Евтеев. - М.: МГИМ0-Университет, 2015. - С. 116-133.

2. Виноградов В.В. Об основных типах фразеологических единиц в русском языке / В.В. Виноградов // Избранные труды: Лексикология и лексикография М.: Наука, 1977. - 230 с.

3. Виноградов В.В. 06 основных типах фразеологических единиц в русском языке / В.В. Виноградов // Избранные труды: Лексикология и лексикография. М.: Наука, 1977. -230 с.

4. У Цзинцзы., Неофициальная история конфуцианцев. Пекин.:1803.405с.

5. Хэ Пин., Энциклопедия Китайских идиом. Чэнду.:издательство электронного научно-технического университета, 2004. $238 \mathrm{c}$.

6. Ц Цяо Юн., Количественное и качественное исследование определения идиом и критериев// Фразеологическое изучение (г.Пекин, апреля 2006). коммерческое издательство, 2006.С.126-128.

(๑) Чэнь Сюе (437118032@qq.com).

Журнал «Современная наука: актуальные проблемы теории и практики» 